Journal of Management and Bussines (JOMB)

Volume 1, Nomor 2, Desember 2019

p-ISSN : 2656-8918

e-ISSN:2684-8317

DOI : https://doi.org/10.31539/jomb.v1i2.698

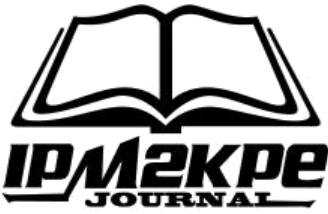

\title{
PERAN KUALITAS PELAYANAN DENGAN APLIKASI PLN MOBILE DALAM MENINGKATKAN KEPUASAN PELANGGAN
}

\author{
Shintya Yuliana ${ }^{1}$, Nor Norisanti ${ }^{2}$, Faizal Mulia ${ }^{3}$ \\ Universitas Muhammadiyah Sukabumi ${ }^{1,2,3}$ \\ shintyayuliana21@gmail.com ${ }^{1}$
}

\begin{abstract}
ABSTRAK
Tujuan dari penelitian ini untuk mengetahui kualitas pelayanan dengan menggunakan Aplikasi PLN Mobile dalam meningkatkan kepuasan pelanggan dengan metode kuantitatif pada PT. PLN (Persero) Rayon Cikembar Kabupaten Sukabumi. Metode penelitian yang digunakan adalah metode Kuantitatif. Teknik analisa yang digunakan adalah uji validitas, uji reabilitas, analisis regresi linear sederhana, termasuk uji koefisien determinasi dan pengujian hipotesis menggunakan pengujian secara parsial (uji t). Hasil penelitian, diperoleh angka R sebesar 0,232 berada pada kategori 0,00 0,199 yang artinya terjadinya hubungan yang rendah antara antara kualitas pelayanan dengan kepuasan pelanggan. Simpulan, masing-masing variabel Kualitas Pelayanan (X) dalam penelitian ini dapat mewakili dari masing-masing variabelnya dan sekaligus dapat dipergunakan oleh peneliti yang akan mendatang.
\end{abstract}

Kata Kunci : Kualitas Pelayanan, Kepuasan Pelanggan.

\section{ABSTRACT}

The purpose of this study is to study the quality of service using the PLN Mobile Application in increasing customer satisfaction with quantitative methods at PT. PLN (Persero) Rayon Cikembar, Sukabumi Regency. The research method used is a quantitative method. The analysis technique used is the validity test, reliability test, simple linear regression analysis, including the coefficient of determination test and hypothesis testing using partial testing ( $t$ test). The results of the study, obtained an $R$ number of 0.232 in the category 0.00 - 0.199, which means a low relationship between service quality and customer satisfaction. Conclusions, each Service Quality (X) variable in this study can represent each variable and can be used by future researchers.

Keywords: Service Quality, Customer Satisfaction.

\section{PENDAHULUAN}

Listrik merupakan salah satu kebutuhan pokok yang digunakan setiap hari. Setiap manusia menggunakan listrik untuk berbagai kebutuhan mulai dari penerangan kebutuhan industri, komunikasi, dan kegiatan lainnya. Di indonesia sendiri listrik adalah satusatunya perusahaan yang dikelola oleh PT.PLN (Persero) dalam naungan Badan Usaha Milik Negara (BUMN) yang mengontrol, menyediakan dan melayani kebutuhan listrik masyarakat. 
Sebagai perusahaan yang menjual produk dan jasa, PT.PLN (Persero) harus memberikan pelayanan terbaik agar dapat menciptakan kepuasan.

Menurut pengamatan singkat yang telah dilakukan beberapa tahun lalu di Kabupaten Sukabumi tepatnya pada PT. PLN (Persero) Rayon Cikembar Kabupaten Sukabumi terhadap keluhan pelayanan pada gangguan rumah terdapat beberapa permasalahan yang berupa keterlambatan pelayanan, ketidakpastian waktu dan biaya pelayanan, serta masih banyak lagi, maka dari itu PT. PLN (Persero) menciptakan PLN Mobile sebagai upaya PLN untuk meningkatkan pelayanan dan komunikasi dengan para pelanggan. "PLN Mobile ini merupakan costumer self service berbasis android yang terhubung dengan layanan online terpusat pengaduan keluhan pada gangguan listrik".

Adapun kelebihan PLN mobile ini para pelanggan bisa mendapatkan segala informasi mulai dari jadwal pemadaman, menyampaikan berbagai keluhan kelistrikan, serta memantau respon pelayanan dari pihak PLN. (sumber: http://metrotvnews.com).

Adanya keluhan-keluhan dari pelanggan merupakan salah satu indikasi adanya masalah mengenai kepuasan pelanggan pada PT. PLN Rayon Cikembar Kabupaten Sukabumi. Permasalahan tersebut diduga disebabkan oleh kualitas pelayanan melalui PLN Mobile belum dilakukan secara maksimal.

\section{TINJAUAN PUSTAKA}

\section{Kualitas Pelayanan}

Kualitas pelayanan merupakan kegiatan yang menghasilkan manfaat serta memberikan keuntungan dalam suatu kegiatan jasa. Definisi pelayanan menurut Kotler jelas bahwa pelayanan adalah suatu kumpulan atau kesatuan yang melakukan kegiatan menguntungkan dan menawarkan suatu kepuasan meskipun hasilnya secara fisik tidak terikat kepada produk (Kotler, 2007).

Dalam Kamus Besar Bahasa Indonesia dinyatakan pengertian pelayanan bahwa "pelayanan adalah suatu usaha untuk membantu menyiapkan (mengurus) apa yang diperlukan orang lain. Sedangkan sedangkan pengertian service dalam Oxford didefinisikan sebagai " a system that provides something that the public needs, organized by the government or a private company”. oleh karenanya fungsi pelayanan sebagai penyedia kebutuhan untuk masyarakat. 
Dalam definisi tersebut dapat dikemukakan bahwa pada dasarnya pelayanan ialah suatu yang tidak berwujud tetapi menghasilkan kegiatan yang bermanfaat bagi orang-orang yang membutuhkan yaitu pelanggan/masyarakat.

Menurut Zeithaml dalam Hardiansyah (2011) menyatakan bahwa "kualitas pelayanan dapat diukur dari 5 dimensi, yaitu Berwujud (Tangible) Kehandalan (Reability), Ketanggapan (Responsiveness), Jaminan (Assurance), dan Empati (empathy)." "Masing-masing memiliki indikator sebagai berikut:

1. Untuk dimensi Tangible (berwujud), terdiri atas indikator:
a. tempat pelayanan yang nyaman
b. proses dan akses layanan mudah
c. pemakaian alat bantu pelayanan

2. Untuk dimensi Kehandalan (Reability), terdiri atas indikator:

a. Ahli menggunakan alat bantu pelayanan

3. Untuk dimensi Respon/Ketanggapan (Responsiveness) terdiri atas indikator:
a. Respon setiap pelangan yang membutuhkan pelayanan
b. Cepat menanggapi keluhan
c. Keluhan pelanggan di respon petugas

4. Untuk dimensi Jaminan (Assurance) terdiri atas indikator:

a. Tepat waktu dalam melaksanakan tugas pelayanan

5. Untuk dimensi Empati (Emphaty) terdiri atas indikator:

a. Mendahulukan kepentingan pelanggan

\section{Kepuasan Pelanggan}

Menurut Oliver dalam Barnes (2003) menyatan bahwa "kepuasan pelanggan adalah tanggapan atas terpenuhinya kebutuhan yang berarti bahwa penilaian pelanggan atas barang dan jasa memberikan sesuai dengan harapan ataupun tidak kepada para pelanggan ." Definisi lain menurut Kotler dan Keller (2009) adalah "perasaan bahagia ataupun kecewa setelah merasakan hasil kinerja yang diharapkan." Sedangkan menurut Chandra, Tjiptono (2005) mendefinisikan "kepuasan pelanggan adalah tanggapan terhadap penilaian ketidaksesuaian yang dirasakan antara harapan sebelumnya dengan kinerja yang dirasakan setelah merasakannya." 
Adapun dimensi kepuasan menurut Irawan (2004) yang disesuaikan dengan kondisi dilapangan, antara lain :

1. Harga (price)

Untuk pelanggan yang gemar membandingkan hasil dan upah, biasanya harga murah adalah sumber kepuasan yang penting karena mereka akan mendapatkan value for money yang tinggi. Komponen dari harga ini adalah tidak penting bagi mereka yang tidak sensitive terhadap harga.

2. Kualitas Pelayanan ( service quality)

Sangat begantung dari beberapa hal yaitu sistem teknologi dan manusia. Kepuasan pelanggan terhadap kualitas pelayanan biasanya sulit ditiru karena pembentukan attitude dan behavior yang sering dengan keinginan perusahaan bukan lah pekerjaan mudah. Pembenahan harus dilakukan dari proses rekuitmen, training, dan budaya kerja.

3. Kualitas Produk (product quality)

Para Pembeli akan puas setelah menggunakan produk tersebut apabila kualitas produk baik.

\section{Faktor Emosional}

Adalah ditunjukan kepada konsumen atas kepuasan yang diperoleh mereka dari menggunakan produk atau jasa dengan menimbulkan rasa bangga dan rasa percaya diri.

5. Kemudahan

Mudah dalam memperoleh produk atau jasa tersebut serta pembayaran dapat membuat pelanggan akan semakin puas.

Kualitas pelayanan sangat berhubungan erat dengan kepusan pelanggan. Kualitas memberikan suatu dorongan kepada pelanggan untuk menjalin ikatan hubungan yang kuat dengan perusahaan.seperti yang diungkapkan oleh Kotler "Kepuasan Pelanggan adalah tingkat seseorang setelah membandingkan kinerja (hasil) yang ia rasakan dibandingkan dengan harapannya. Dengan demikian kebutuhan penerima layanan harus dipenuhi agar mereka dapat memperoleh kepuasan yang sesuai." 


\section{METODE PENELITIAN}

Penelitian ini dilaksanakan di PT.PLN (Persero) Rayon Cikembar Kabupaten Sukabumi. Metode penelitian yang digunakan adalah kuantitatif. Untuk Sampel yang digunakan dalam penelitian ini adalah jenis teknik sampling dengan melakukan penyebaran kuesioner sebanyak 100 kepada para pelanggan PT. PLN (Persero) Rayon Cikembar Kabupaten Sukabumi. Teknik analisa yang digunakan adalah uji validitas, uji reabilitas, regresi linear sederhana, termasuk uji koefisien determinasi, koefisien korelasidan pengujian hipotesis menggunakan uji secara parsial (uji t).

\section{HASIL PENELITIAN}

\section{Uji Validitas}

Uji validitas adalah suat taraf dmana alat pengukur dapat mengukur apa yang seharusnya diukur, sehingga suatu penelitian yang menggunakan kuesioner sebagian besar pengukurannya perlu diuji validitasnya. Biasanya syarat minimum untuk memenuhi syarat adalah kalau $r=0,3$. Jadi jika korelasi antara butir dan skor total kurang dari 0,3 maka butir instrument dinyatakan tidak valid.

Berdasarkan pengujian validitas dengan menggunakan bantuan software SPSS 24 diperoleh hasil sebai berikut :

Tabel 1 Hasil Uji Validitas

\begin{tabular}{ccccc}
\hline 0 & Item & r-hitung & r-kritis & Keterangan \\
\hline Kualitas Pelayanan (X) & 1 & 0,346 & 0,3 & Valid \\
& 2 & 0,547 & 0,3 & Valid \\
& 3 & 0,617 & 0,3 & Valid \\
& 4 & 0,483 & 0,3 & Valid \\
& 5 & 0,476 & 0,3 & Valid \\
& 6 & 0,454 & 0,3 & Valid \\
& 7 & 0,415 & 0,3 & Valid \\
Kepuasan Pelanggan (Y) & 8 & 0,416 & 0,3 & Valid \\
& 9 & 0,483 & 0,3 & Valid \\
\hline & 1 & 0,493 & 0,3 & Valid \\
& 2 & 0,704 & 0,3 & Valid \\
& 3 & 0,629 & 0,3 & Valid \\
& 4 & 0,580 & 0,3 & Valid \\
& 5 & 0,561 & 0,3 & Valid \\
& 6 & 0,517 & 0,3 & Valid \\
\hline
\end{tabular}


Berdasarkan data tabel diatas dapat diketahui bahwa nilai korelasi antara skor item variabel Kualitas Pelayanan (X) dan Kepuasan Pelanggan bahwa seluruh item pada hasil pengujian tersebut memiliki skor diatas 0,3 sehingga seluruh butir instrumen item Kualitas Pelayanan (Y) dan Kepuasan Pelanggan dinyatakan valid.

\section{Uji Relibilitas}

Hasil uji reliabilitas dengan menggunakan rumus Cronbach's Alpha dengan bantuan SPSS 24 adalah sebagai berikut:

Tabel 2 Hasil Uji Reliabilitas

\begin{tabular}{lccc}
\hline Variabel & \multicolumn{2}{c}{ Koefisien Cronbach's Alpha } & Keterangan \\
\hline & Hitung & Standar & \\
Kualitas pelayanan (X) & 0,690 & 0,6 & Reliabel \\
Kepuasan pelanggan (Y) & 0,721 & 0,6 & Reliabel \\
\hline Sumber: Data Primer (Kuesioner), 2019 &
\end{tabular}

Dari tabel 2 diatas diperoleh hasil yang menunjukkan bahwa $\alpha$ hitung $>\alpha$ standar $(0,6)$ sehingga dapat disimpulkan bahwa variabel-variabel yang dipakai dalam penelitian ini adalah reliabel. Dengan demikian maka jelaslah bahwa variabel-variabel tersebut dapat digunakan untuk penelitian selanjutnya karena dapat diandalkan.

\section{Koefisien Korelasi Sederhana}

Tabel 3 Hasil Koefisien Korelasi Sederhana

\begin{tabular}{|c|c|c|c|c|}
\hline \multicolumn{5}{|c|}{ Model Summary } \\
\hline Model & $\mathrm{R}$ & R Square & $\begin{array}{c}\text { Adjusted R } \\
\text { Square }\end{array}$ & $\begin{array}{c}\text { Std. Error of the } \\
\text { Estimate }\end{array}$ \\
\hline 1 & $.232^{\mathrm{a}}$ & .054 & .044 & 3.851 \\
\hline
\end{tabular}

a. Predictors: (Constant), Kualitas Pelayanan

Sumber: Data Primer(Kuesioner), 2019

Berdasarkan tabel 3 diatas diperoleh angka $\mathrm{R}$ sebesar 0,232 berada pada kategori $0,00-0,199$. Hal ini merupakan bahwa terjadinya hubungan yang rendah antara antara kualitas pelayanan dengan kepuasan pelanggan. 


\section{Koefisien Determinasi $\left(\mathbf{R}^{2}\right)$}

Tabel 4 Hasil Koefisien Determinasi

\begin{tabular}{lc|c|c|c}
\hline \multicolumn{4}{c}{ Model Summary } \\
Model & $\mathrm{R}$ & $\mathrm{R}$ Square & $\begin{array}{c}\text { Adjusted R } \\
\text { Square }\end{array}$ & $\begin{array}{c}\text { Std. Error of the } \\
\text { Estimate }\end{array}$ \\
\hline 1 & $.232^{\mathrm{a}}$ & .054 & .044 & 3.851 \\
\hline a. Predictors: (Constant), Kualitas Pelayanan & \\
\hline
\end{tabular}

Sumber: Data Primer(Kuesioner), 2019

Berdasarkan hasil tabel 4 diatas model summary menyatakan besarnya adjusted $\mathrm{R}^{2}$ sebesar 0,044 hal ini berarti $4,4 \%$.

\section{Hasil Analisis Regresi Liner Sederhana}

Tabel 5 Hasil Analisis Regresi Linear Sederhana

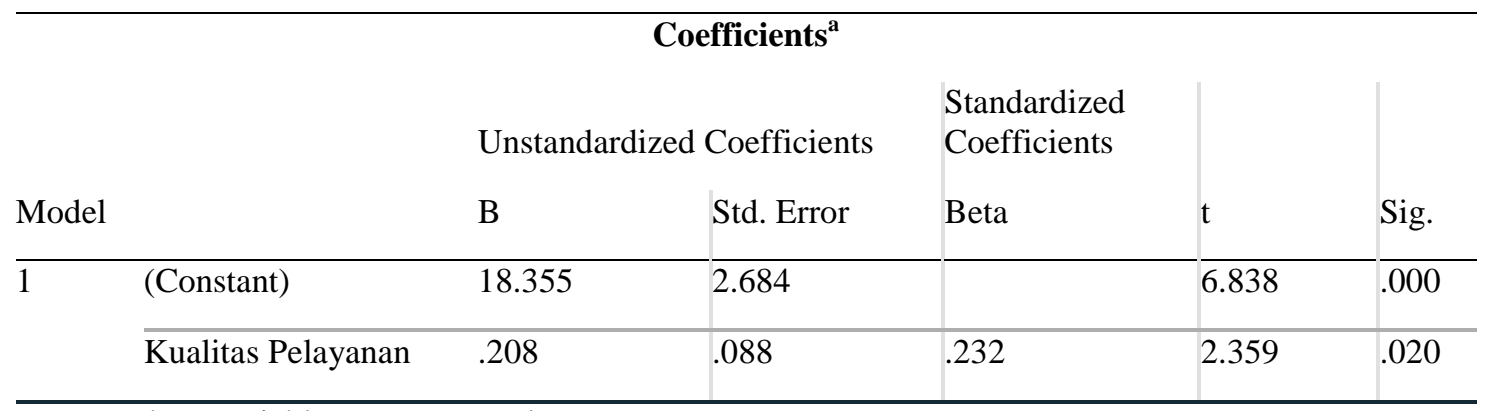

a. Dependent Variable: Kepuasan Pelanggan

Sumber: Data Primer (Kuesioner), 2019

Dari output uji regresi linear sederhana diatas maka dapat diperoleh persamaan sebagai berikut:

$$
Y=18,355+0,208 X
$$

\section{Uji Signifikan Secara Parsial (Uji T)}

Tabel 6 Uji T

\begin{tabular}{|c|c|c|c|c|c|c|}
\hline \multicolumn{7}{|c|}{ Coefficients $^{\mathrm{a}}$} \\
\hline & & \multicolumn{2}{|c|}{ Unstandardized Coefficients } & \multirow{2}{*}{$\begin{array}{c}\text { Standardized } \\
\text { Coefficients } \\
\text { Beta }\end{array}$} & \multirow[b]{2}{*}{$\mathrm{t}$} & \multirow[b]{2}{*}{ Sig. } \\
\hline & Model & B & Std. Error & & & \\
\hline 1 & (Constant) & 18.355 & 2.684 & & 6.838 & .000 \\
\hline & tas Pelayanan & .208 & .088 & .232 & 2.359 & .020 \\
\hline
\end{tabular}


Berdasarkan tabel 6 diatas hasil uji t yang dilakukan dapat diperoleh nilai Sig. $0,000<0,05$; nilai $t_{\text {hitung }} 2.359$

\section{PEMBAHASAN}

Diketahui bahwa variabel kualitas pelayanan terhadap kepuasan pelanggan PT. PLN (Persero) Rayon Cikembar Kabupaten Sukabumi. Dapat dilihat dari tanggapan responden yang memberikan penilaian puas pada kualitas yang diberika PT. PLN. Sebagaimana yang diungkapkan oleh Herri Afaendi (2017) bahwa kualitas pelayanan berpengaruh signifpase ikan terhdap kepuasan pelanggan di Perusahaan Daerah Air Minum PDAM Tirta Mon Kabupaten Utara.

Kualitas pelayanan sangat berhubungan erat dengan kepusan pelanggan. Kualitas memberikan suatu dorongan kepada pelanggan untuk menjalin ikatan hubungan yang kuat dengan perusahaan.seperti yang diungkapkan oleh Kotler "Kepuasan Pelanggan adalah tingkat seseorang setelah membandingkan kinerja (hasil) yang ia rasakan dibandingkan dengan harapannya. Dengan demikian kebutuhan penerima layanan harus dipenuhi agar mereka dapat memperoleh kepuasan yang sesuai."

Menurut Oliver dalam Barnes (2003) menyatan bahwa "kepuasan pelanggan adalah tanggapan atas terpenuhinya kebutuhan yang berarti bahwa penilaian pelanggan atas barang dan jasa memberikan sesuai dengan harapan ataupun tidak kepada para pelanggan ." Definisi lain menurut Kotler dan Keller (2009) adalah "perasaan bahagia ataupun kecewa setelah merasakan hasil kinerja yang diharapkan." Sedangkan menurut Chandra, Tjiptono (2005) mendefinisikan "kepuasan pelanggan adalah tanggapan terhadap penilaian ketidaksesuaian yang dirasakan antara harapan sebelumnya dengan kinerja yang dirasakan setelah merasakannya."

\section{SIMPULAN}

Dari hasil diatas dapat disimpulkan bahwa masing-masing variabel Kualitas Pelayanan (X) dalam penelitian ini dapat mewakili dari masing-masing variabelnya dan sekaligus dapat dipergunakan oleh peneliti yang akan mendatang. 


\section{DAFTAR PUSTAKA}

Affandi. H., Zaki, M., Azmeri, A. (2017). Pengaruh Kualitas Pelayanan terhadap Kepuasan Pelanggan pada Perusahaan Daerah Air Minum (PDAM) Tirta Mon Pase Kabupaten Aceh Utara. Jurnal Teknik Sipil, 6(3), 297-308

Barnes, J. G., Asparyogi, A. (2003). Secrets of Costumer Relationship Management. Diterjemahkan oleh Andreas Winardi, Yogyakarta: Penerbit Andi

Tjiptono, F., Chandra, G. (2005). Manajemen Kualitas Jasa. Yogyakarta: ANDI

Irawan, H. (2004). Kepuasan Pelayanan Jasa. Jakarta: Erlangga

Hardiasyah, H. (2011). Kualitas Pelayanan Publik. Yogyakarta: Gava Media

Kotler, P., Keller, K. L. (2007). Manajemen Pemasaran. Jakarta: PT Indeks

Kotler, P., Keller, K. L. (2009). Manajemen Pemasaran. Jilid I. Edisi ke 13 Jakarta: Erlangga 